\title{
Biology and clinical application of CAR $T$ cells for $B$ cell malignancies
}

\author{
Marco L. Davila ${ }^{1} \cdot$ Michel Sadelain $^{2}$
}

Received: 18 April 2016 / Revised: 31 May 2016 / Accepted: 31 May 2016 / Published online: 4 June 2016

(C) The Japanese Society of Hematology 2016

\begin{abstract}
Chimeric antigen receptor (CAR)-modified $\mathrm{T}$ cells have generated broad interest in oncology following a series of dramatic clinical successes in patients with chemorefractory B cell malignancies. CAR therapy now appears to be on the cusp of regulatory approval as a cell-based immunotherapy. We review here the $\mathrm{T}$ cell biology and cell engineering research that led to the development of second generation CARs, the selection of CD19 as a CAR target, and the preclinical studies in animal models that laid the foundation for clinical trials targeting CD19+ malignancies. We further summarize the status of CD19 CAR clinical therapy for non-Hodgkin lymphoma and B cell acute lymphoblastic leukemia, including their efficacy, toxicities (cytokine release syndrome, neurotoxicity and B cell aplasia) and current management in humans. We conclude with an overview of recent pre-clinical advances in CAR design that argues favorably for the advancement of CAR therapy to tackle other hematological malignancies as well as solid tumors.
\end{abstract}

Keywords Adoptive $\mathrm{T}$ cell therapy $\cdot$ Chimeric antigen receptor $\cdot \mathrm{CD} 19 \cdot \mathrm{Immunotherapy} \cdot \mathrm{T}$ cell engineering

Marco L. Davila

marco.davila@moffitt.org

1 Department of Blood and Marrow Transplantation, H. Lee Moffitt Cancer Center and Research Institute, 12902 Magnolia Drive, Tampa, FL 33612, USA

2 Center for Cell Engineering, Memorial Sloan Kettering Cancer Center, New York, NY, USA

\section{Introduction}

Following a decade of preclinical optimization, CD19 chimeric antigen receptor (CAR) therapy has rapidly made a high impact in oncology. Within a few years, the CAR field has progressed from fledgling reports of anecdotal responses in patients with non-Hodgkin lymphoma (NHL) or chronic lymphocytic leukemia (CLL) to achieving reproducible outcomes in hundreds of patients with $\mathrm{B}$ cell malignancies, most strikingly in B cell acute lymphoblastic leukemia (B-ALL). These clinical results have generated unprecedented interest in cell-based therapies and sparked large-scale engagement in the biotechnology and pharmaceutical sectors. It now appears plausible that the commonly fatal relapsed/refractory B-ALL will be the first clinical indication for CAR T cells, which will hopefully usher in a new era of T cell-based, targeted cancer immunotherapies. We summarize here the pre-clinical development of CARs, their adaptation for use in patients, the present clinical experience with CD19 CAR T cells, and finally the future direction of this disruptive cancer therapy.

\section{Biological functions of CARs}

$\mathrm{T}$ cells are a component of the adaptive immune system, which includes CD4+ and CD8+ T cells capable of recognizing and eliminating virus-infected cells and cancer cells [1]. Antigen recognition is mediated by the $\mathrm{T}$ cell receptor (TCR), which binds to peptides presented by major histocompatibility complex (MHC) proteins expressed on the cell surface. While the TCR binds the MHC/peptide complex, it is not sufficient to mediate signaling. Instead, the TCR heterodimer serves to engage antigen and secondarily 
Fig. 1 Second generation CAR structure. A common CAR design, depicted here, comprises a signal peptide (SP) followed by the $\mathrm{scFv}$, which is composed of $\mathrm{IgH}$ and $\mathrm{IgL}$ rearrangements separated by a linker such as the glycine-serine $(\mathrm{G} / \mathrm{S})$ linker. A linker domain of variable length, followed by a transmembrane region is followed by costimulatory and activation domains. The synthetic CAR cDNA is encoded by a vector used to transduce patient $\mathrm{T}$ cells. The resulting CAR T cells are thus targeted to the tumor and functionally enhanced
CAR cDNA

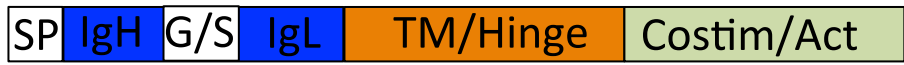

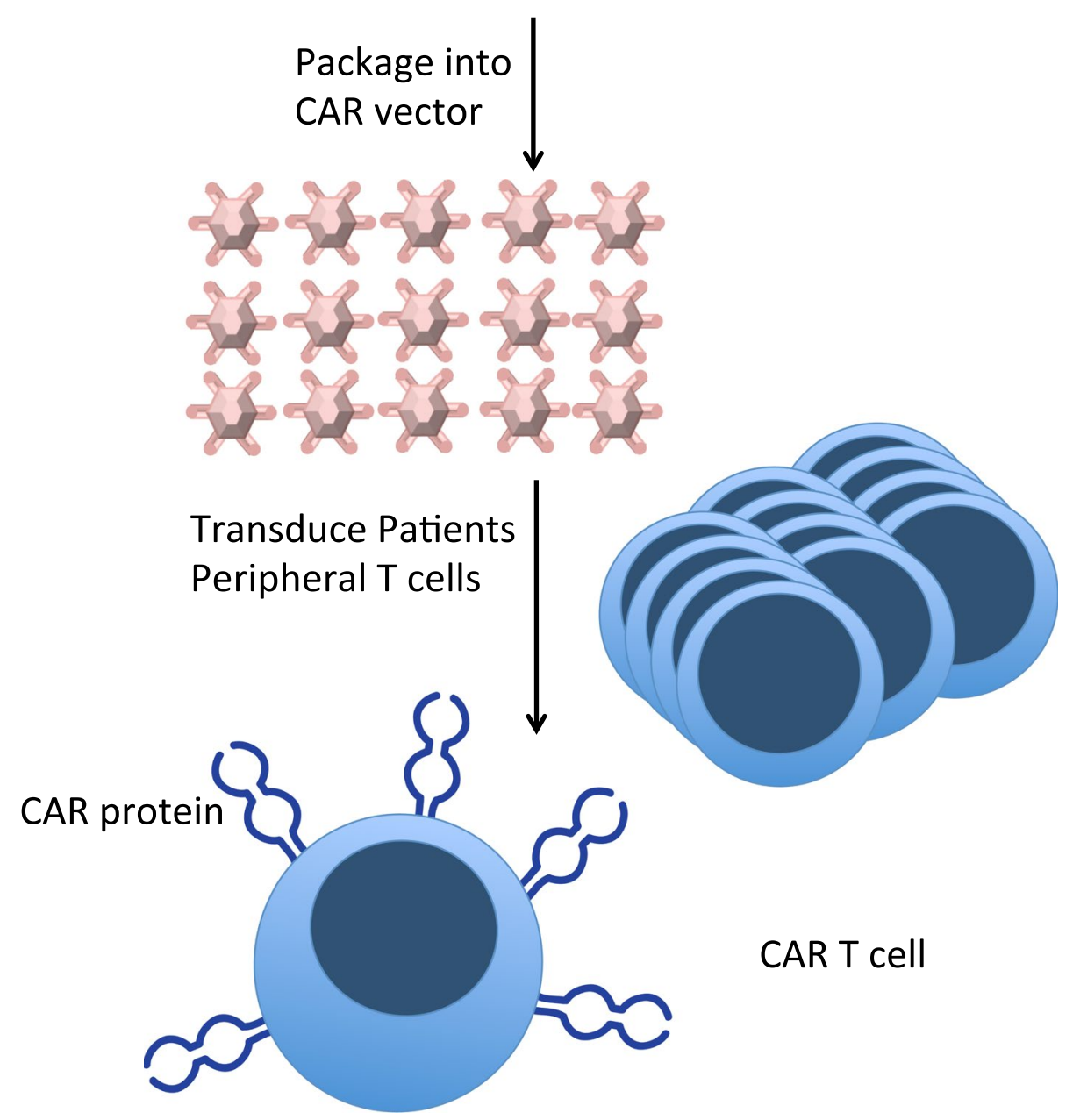

cluster CD3 to initiate T cell activation [2]. The CD3 complex comprises two homodimers of $\mathrm{CD} 3 \zeta$, a heterodimer of $\mathrm{CD} 3 \varepsilon$ and $\mathrm{CD} 3 \delta$, and another heterodimer of $\mathrm{CD} 3 \varepsilon$ and $\mathrm{CD} 3 \gamma$. T cell activation is initiated through the immunoreceptor tyrosine-based activation motifs (ITAMs) present in the CD3 polypeptides [2]. In the early 1990's, the T cell biologists who cloned the $\mathrm{CD} 3 \zeta$ chain created chimeric $\zeta$ chain receptors and determined that $\mathrm{T}$ cell activation could be induced by antibody cross-linking of these $\zeta$ chain fusion receptors [3-5]. Two other groups then derived a simplified receptor for antigen that fused the $\zeta$ chain to a single chain variable fragment $(\mathrm{scFv})$ as its extracellular domain $[6,7]$, thus creating a TCR-like molecule encoded by a single cDNA. Zelig Eshhar named the hybrid protein a "T-body" [6], which we later renamed a first generation CAR [8]. Studies in human primary T cells [9] and in transgenic mice [10] soon demonstrated the shortcomings of these receptors. However, based on earlier studies conducted in human primary $\mathrm{T}$ cells that had established that costimulation could be bestowed onto T cells through a chimeric costimulatory receptor (CCR) [11], a novel engineering strategy was proposed to design a receptor endowed with dual signaling capabilities-activation together with costimulation, which enabled $\mathrm{T}$ cell cells to expand and retain function upon repeated exposure to antigen [12]. We named such receptors second generation CARs (Fig. 1) [8]. CARs may utilize an $\mathrm{scFv}$ or any alternative ligand to bind their target antigen, and are thus independent of MHC, unlike the physiological TCR. The targeted antigen has to be on the target cell surface and may be a protein, a carbohydrate or a glycolipid. CAR T cells, therefore, express two receptors for antigen: their endogenous TCR and the transduced CAR.

Over the past 30 years, a number of investigators have demonstrated the utility of isolating, expanding, and reinfusing tumor-reactive T cells back into patients. Alternatively, one may engineer readily available peripheral blood lymphocytes, which provides several advantages. First of 
all, the isolation of sparse tumor-specific $\mathrm{T}$ cells from a surgical tumor specimen and subsequent ex vivo expansion may require extensive culture to generate a number of $\mathrm{T}$ cells sufficient for infusion back into the patient [13]. In contrast, the genetic modification of a bulk population of $\mathrm{T}$ cells with a CAR rapidly provides tumor-targeted cells in sufficient number, typically within 10 days [14]. Second, TCR recognition of tumor-derived peptides requires presentation by $\mathrm{MHC}$, which are highly polymorphic and preclude the use of a single TCR for all patients. In contrast, CARs are HLA-independent receptors for antigen and thus can be used in any patient regardless of their MHC. Third, the versatility of antibody generation and heavy and light chain library screening greatly facilitates the construction of CARs specific for any molecule including proteins, carbohydrates, lipids, DNA, and even MHC-peptide complexes. Lastly, CARs are modular, synthetic proteins that can be further modified to potentiate or attenuate $\mathrm{T}$ cell functions to achieve a desired outcome. The best known second generation CARs utilize the CD28 [12] or 4-1BB costimulatory signaling domains [15], reviewed in [16]. Other costimulatory domains, such as OX40, CD27, ICOS and NKG2D, have been described [16] and remain to be further compared to the canonical CD28/CD3 $\zeta$ and 4-1BB/ $\mathrm{CD} 3 \zeta$ dual-signaling receptors.

\section{Production of engineered CAR T cells for clinical use}

The clinical evaluation of CAR $\mathrm{T}$ cells requires a safe, efficient and reproducible CAR $\mathrm{T}$ cell production process following good manufacturing practices (GMP). Over the last 10 years, a few academic GMP facilities have developed and refined protocols and systems for CAR $\mathrm{T}$ cell production [17]. The most efficient and rapid means to genetically target $\mathrm{T}$ cells to an antigen is by viral vector transduction, using gamma-retroviral or lentiviral vectors (Fig. 1). Electroporation of RNA or DNA also have been evaluated in pre-clinical and, to a very limited extent, clinical research $[18,19]$. While the latter gene transfer systems can achieve adequate CAR expression levels, the length of culture (from weeks to months) required in some instances may limit the overall function of the adoptively transferred $\mathrm{T}$ cells. Retroviral vector transduction can produce a sufficient dose of genetically modified $\mathrm{T}$ cells in as little as 1 week [17] and has thus become the favored system for clinical $\mathrm{T}$ cell genetic modification.

The two commonly utilized retroviral transduction systems are gamma-retroviral and lentiviral vectors [17, 20]. One advantage of gamma-retroviral vectors is their streamlined manufacturing process, which takes advantage of stable packaging cell lines and does not require downstream concentration and purification [21]. Lentiviral vectors are very effective as well, but their manufacture requires repeated large-scale transfections, and further purification and concentration of every vector lot. Randomly integrating vectors (gamma-retroviral vectors, lentiviral vectors, transposons), however, pose a general concern due to the potential genotoxicity of proto-oncogene trans-activation, which could result in insertional oncogenesis, and variegated transgene expression, which results in variable CAR expression and eventual transgene silencing. Insertional oncogenesis has occurred in patients infused with genetically modified hematopoietic stem or progenitor cells as a treatment for immune deficiencies [22, 23]. The risk/benefit analysis is, however, quite different in the setting of CAR T cell therapy. First, the risk of oncogenic transformation of $\mathrm{T}$ cells is far less than for hematopoietic progenitors. Second, T cell persistence is generally less than 1-year, which is less than the premalignant phase associated with vector integration-associated leukemia. Third, the risk assessment is different in cancer patients with relapsed, refractory and/ or metastatic disease who are enrolled on CAR protocols. Satisfyingly, this anticipated low-risk for clonal $\mathrm{T}$ cell expansion or insertional oncogenesis has so far held true, as no such events have been reported to date in the first hundreds of patients treated with CD19 CAR T cells. The targeted integration of the CAR cDNA into a safe locus may alleviate the concerns associated with all randomly integrating vector systems [24].

CAR T cell production begins with collection of $\mathrm{T}$ cells from the patient, which is accomplished by leukapheresis. $\mathrm{T}$ cells are isolated and activated by antibodies specific for CD3 and/or CD28 [17], which induces T cell activation and proliferation thereby rendering the cells more susceptible to viral transduction. The transduced cells are expanded until the required CAR T cell dose is achieved. End-ofproduction CAR $\mathrm{T}$ cells then undergo pre-defined quality control and assurance assays to confirm function and sterility before the product is released for clinical use. The T cell collection, isolation, genetic modification, expansion, and QC/QA process reliably results in a CAR $\mathrm{T}$ cell product within 1-2 weeks.

\section{The early phase experience with CAR $T$ cells as a cancer immunotherapy}

\section{Non-Hodgkin lymphoma (2008-2012)}

The initial clinical evaluation of CAR T cells focused on indolent $\mathrm{B}$ cell malignancies (Table 1). The rationale for first investigating chronic lymphocytic leukemia (CLL) or follicular lymphoma was that indolent malignancies would afford ample time to collect patients $\mathrm{T}$ cells and genetically 
target them to CD19 without concerns for delaying treatment of a rapidly progressing cancer. In just 4 years, eight reports from six different academic groups described the outcome of infusing $38 \mathrm{NHL}$ patients with 1 st and/or 2nd generation CAR T cells targeted to CD19 (or CD20 in one report) $[18,20,25-30]$. While most patients did not have objective responses, there were important outcomes that informed subsequent CAR $\mathrm{T}$ cell trials. Three groups infused first-generation CARs, the Baylor College of Medicine (BCM), the City of Hope, and the Fred Hutchinson Cancer Research Center (FHCRC) [18, 25, 26]. In these early phase trials, patients were treated with CAR T cells without prior conditioning chemotherapy and CAR T cell doses ranged from $2 \times 10^{7}$ to $3 \times 10^{9}$ CAR T cells/ $\mathrm{m}^{2}$. None of these three groups could identify objective responses clearly attributable to CAR $\mathrm{T}$ cell activity-consistent with the limitations of the T-body/first generation CAR design. However, patients enrolled at BCM were infused with a mixture of second-generation and first-generation CD19-targeted CAR T cells to determine the clinical importance of CAR design. Savoldo et al. [25] demonstrated enhanced expansion and persistence of $\mathrm{T}$ cells with a second-generation CAR containing a CD28 co-stimulatory domain, confirming earlier findings obtained with human CAR T cells in murine models [31]. The group at Memorial Sloan Kettering Cancer Center (MSKCC) also demonstrated conditioning chemotherapy given before infusion of T cells with a CD19-targeted CAR (19-28z), which included a CD28 co-stimulatory domain, significantly enhanced the expansion and persistence of adoptively transferred CAR T cells [27]. This was a Phase I trial including patients treated with or without prior conditioning chemotherapy and CAR T cell doses from $0.4 \times 10^{6}$ to $3 \times 10^{7} \mathrm{CAR} \mathrm{T}$ cells $/ \mathrm{kg}$. The collective results from these four trials suggested that optimal CAR $\mathrm{T}$ cell function requires second-generation CAR designs, as well as preinfusion conditioning chemotherapy.

The next trials evaluating CD19 CAR T cells provided the first clear evidence of clinical activity against indolent $\mathrm{B}$ cell malignancies and was reported by investigators at the National Cancer Institute (NCI) and the University of Pennsylvania (UPENN). These groups utilized significant host conditioning chemotherapy consisting of cyclophosphamide and fludarabine or bendamustine, respectively. In case reports from both centers, a NHL patient underwent rapid resolution of their disease after treatment with conditioning chemotherapy followed by infusion with $\mathrm{T}$ cells modified with a second-generation CAR $[28,30]$. The NCI infused $4 \times 10^{8}$ CAR T cells modified with a 19-28z-like CAR containing the identical CD28 extracellular, transmembrane and co-stimulatory domain as in the MSKCC $19-28 \mathrm{z}$ CAR, fused to an scFv derived from the FMC63 antibody [32]. The UPENN case report used the second-generation 
CAR with a 41BB co-stimulatory domain instead of CD28 [15] and a lower T cell dose of $1.5 \times 10^{5} \mathrm{CAR} T$ cells/ $\mathrm{kg}$ [28]. The objective responses were attributed to CAR T cell function on the basis of the prolonged ( $>10$ months) B cell aplasia seen in both patients, which was likely due to normal B cell elimination by CD19 CAR T cells. In addition, both groups described toxicities that were characterized by a large elevation of serum cytokines and fevers, which were later described as part of the cytokine release syndrome (CRS). These CRS toxicities, which were coincident with tumor eradication, provided evidence of CAR $\mathrm{T}$ cell activation and thus supported the notion that the CAR T cells exerted therapeutic anti-tumor effects. When the NCI expanded their cohort to 8 NHL patients treated with CY/Flu conditioning chemotherapy followed by CAR $\mathrm{T}$ cells $\left(0.5 \times 10^{7}-5.5 \times 10^{7} \mathrm{CAR} \mathrm{T}\right.$ cells $\left./ \mathrm{kg}\right)$, they only reported a single complete remission (CR) [29]. The most common NHL subtype treated among the early CAR T trials was CLL, which accounted for 14 patients, and there were 3 CRs in this group, for a modest CR rate of $21 \%$ [33]. Despite limited overall efficacy, the occurrence of occasional CRs suggested that CAR $\mathrm{T}$ cell immunotherapy be further evaluated.

\section{Non-Hodgkin lymphoma (2014-2015)}

There have been two major updates of NHL patients treated with autologous CD19-targeted second-generation CAR $T$ cells (Table 1). The UPENN group [34] recently published their updated experience with 19BBz CAR T cells for patients with relapsed/refractory CLL, while the NCI [35] reported an expanded cohort of 15 patients with NHL with the most common subtypes being diffuse large B cell lymphoma (DLBCL, five patients), CLL (four patients), and primary mediastinal B cell lymphoma (four patients). UPENN pre-treated CLL patients with a conditioning chemotherapy that was also a standard chemotherapy regimen and the total CAR T cell dose ranged from $0.14 \times 10^{8}$ to $11 \times 10^{8}$ CAR T cells. The UPENN original cohort of three patients [20] was expanded to include a total of 14 patients [34]. The updated CR rate is $29 \%$ and objective response rate (ORR) is $57 \%$. The NCI study included four CLL patients and three were induced into a CR [35]. In total, the CR rate for both trials $(\mathrm{CR}=44 \%, 7 / 18)$ improved from the early trials with NHL. The difference in efficacies between the UPENN and NCI groups may be related to the more aggressive conditioning chemotherapy given to NCI patients. Indeed, the NCI reported at the 2014 ASH meeting, a CR rate of only $23 \%$ when providing a lower-dose conditioning regimen prior to CD19 CAR T cell infusion [36]. This suggests that the conditioning chemotherapy may provide an anti-lymphoma benefit as well. Furthermore, the higher $\mathrm{CR}$ rate associated with increased conditioning chemotherapy comes with worsened toxicity since $87 \%$ of those subjects had $\geq$ grade 3 non-hematologic toxicities [35].

The durability of the remissions reported by the NCI and UPENN is impressive with all CLL patients treated in both groups maintaining CR at the time of report. The UPENN data [34] suggests that CAR T cell expansion and persistence appear to correlate with response since all patients with a CR and two with PRs have evidence or persistent B cell aplasia. In addition to the four CLL patients treated by the NCI, the other most common subtypes in the cohort was Diffuse Large B cell lymphoma (DLBCL, five patients) and primary mediastinal B cell lymphoma (four patients) [35]. Patients were conditioned with fludarabine and cyclophosphamide followed by $1928 \mathrm{z}$ CAR T cells with doses ranging from $1 \times 10^{6}$ to $5 \times 10^{6} \mathrm{CAR} \mathrm{T}$ cells $/ \mathrm{kg}$. Responses were impressive with an ORR of $73 \%(8 / 11)$ and $\mathrm{CR}$ rate of $45 \%(5 / 11)$ with four ongoing. It did not appear that the 1928z CAR T cells persisted longer than 2-3 months and there was no clear correlation between persistence or expansion with clinical outcomes.

\section{Non-Hodgkin lymphoma (American Society of Hematology 2015 update)}

At the American Society of Hematology (ASH) 2015 meeting, important updates were presented for NHL. FHCRC investigators described results from a trial including 34 patients with relapsed/refractory NHL treated with T cells modified with the 19BBz CAR [37]. The large majority of patients had diffuse large B cell lymphoma (DLBCL, $n=18$ ) with the remainder having follicular lymphoma $(n=6)$, CLL $(n=6)$, or mantle cell lymphoma $(n=4)$. The CD19-targeted CAR T cells infused were of a defined subset, a fixed 1:1 ratio of CD8+ T central memory cells to CD4+ T cells. The doses were $2 \times 10^{5}, 2 \times 10^{6}$, and $2 \times 10^{7}$ CAR T cells/kg [37]. They also compared conditioning chemotherapy that included cyclophosphamide and fludarabine or cyclophosphamide without fludarabine. They reported increased CAR T cell persistence and expansion in patients treated with fludarabine and cyclophosphamide, which had clinical implications because they noted an improved CR rate ( 42 vs. $8 \%$ ) compared to patients treated with cyclophosphamide alone [37]. Since the NCI uses a similar conditioning regimen for NHL it suggests a reason for the high response rates observed by the NCI [35]. In the cohort treated by the FHCRC with optimal conditioning chemotherapy, CR rates were $38 \%(3 / 8)$ for DLBCL and $67 \%(2 / 3)$ for follicular lymphoma. In addition, the CR rate for CLL was $50 \%(n=3 / 6)$ demonstrating improved outcomes from the early trials targeting CLL, most likely due to improved conditioning chemotherapies. They also identified a potential cause for poor persistence 
of CAR T cells, due to cell-mediated anti-murine scFv T cell responses. Thus, a benefit of including fludarabine in the conditioning may be to minimize host $\mathrm{T}$ cell immune responses to the CAR.

UPENN investigators also presented results of their phase II study treating 22 patients with follicular lymphoma, mantle cell lymphoma (MCL), or DLBCL [38]. All patients received conditioning chemotherapy but regimens varied and the median CAR T cell dose was $5.8 \times 10^{6}$ CAR T cells $/ \mathrm{kg}$. The three-month ORR reported was $54 \%$ (7/13) for DLBCL, $100 \%$ for follicular lymphoma (7/7), and $50 \%$ for MCL (1/2) [38]. In a Phase I/II trial sponsored by Kite Pharma, DLBCL was again demonstrated to be sensitive to $19-28 \mathrm{z}$ CAR T cells [39]. In this trial all patients were conditioned with cyclophosphamide and fludarabine followed by a CAR T cell infusion of $2 \times 10^{6}$ CAR T cells $/ \mathrm{kg}$. Five out of seven patients were re-induced into a CR with three of the CRs classified as ongoing at 3 months follow-up [39].

In the 8 years since the first report targeting NHL with CAR T cells the field has progressed from anecdotal proofof-principle responses to reproducible, and efficacious, objective responses for subsets of NHL. The cumulative research efforts of several groups have identified a requisite conditioning chemotherapy regimen, efficacious and safe CAR T cell dose range, optimal CAR design, and susceptible NHL subsets that have poor clinical outcomes and are in need of novel therapies. Relapsed DLBCL and follicular lymphoma now need to be further evaluated in larger, multi-center clinical trials. Despite these successes, more work remains with other NHL subsets, such as CLL. This disease may be more resistant to immune interventions due to inhospitable tumor microenvironments or the $\mathrm{T}$ cells from these patients may be more consistently impaired than in other B cell malignancies. It was recently demonstrated that CLL patients treated previously with ibrutinib before $\mathrm{T}$ cell collection and CAR $\mathrm{T}$ cell production had improved CAR T cell expansion after transfer back into patients [40]. Targeting CLL will likely require either more advanced CAR designs [41], further optimizing of conditioning regimens, or novel CAR T cell combination therapies, such as with ibrutinib.

\section{B cell acute lymphoblastic leukemia (2013-2015)}

The early experience with CD19 CAR T cells for NHL suggested the potential of CAR therapy for B cell malignancies, but it is the remarkable efficacy against B-ALL that truly asserted CAR therapy as a game changer. In 2 years, three academic groups published five reports detailing clinical trials and outcomes with CD19-targeted CAR T cells for adults and children with relapsed/refractory B-ALL [42-46]. In total, 67 patients (21 adults, 45 children/young adults) were treated (Table 2). The first demonstration came from MSKCC [43] in a report on five adults with relapsed, chemorefractory disease, which was expanded the next year to 16 patients [42]. This was a Phase I trial using the 19-28z CAR with a CAR T cell dose of $3 \times 10^{6}$ CAR T cells $/ \mathrm{kg}$. Patients were treated with cyclophosphamide alone as a conditioning chemotherapy before CAR $\mathrm{T}$ cell transfer. While there was concern whether a sufficient number of $\mathrm{T}$ cells could be collected and genetically modified with the CAR because B-ALL patients are commonly pancytopenic due to aggressive lymphodepleting

Table 2 Summary of published clinical trials of CD19 CAR T cell therapy for relapsed/refractory B-ALL

\begin{tabular}{|c|c|c|c|c|c|c|c|c|c|}
\hline References & Site & $n$ & Median age & Post Allo-SCT & CAR T dose $/ \mathrm{kg}$ & $\mathrm{CR}(\%)$ & $\operatorname{CRm}(\%)$ & EFS & Notes \\
\hline $\begin{array}{l}\text { Davila } \\
\text { et al. [42], } \\
\text { Brentjens } \\
\text { et al. [43] }\end{array}$ & MSKCC & 16 & 50 & $25 \%$ & $3 \times 10^{6}$ & 88 & 75 & NA & $\begin{array}{l}\text { All adults } \\
1 \text { Patient received } \\
\text { less than the } \\
\text { study dose }\end{array}$ \\
\hline $\begin{array}{l}\text { Maude et al. } \\
\text { [44] Grupp } \\
\text { et al. [45] }\end{array}$ & UPENN $^{a}$ & $\begin{array}{r}25^{\mathrm{b}} \\
5 \#\end{array}$ & $\begin{array}{l}11^{\mathrm{b} \#} \\
47\end{array}$ & $60 \%$ & $\begin{array}{r}0.8 \times 10^{6}- \\
21 \times 10^{6}\end{array}$ & 90 & 73 & $\begin{array}{l}67 \% \text { at } \\
6 \text { months }\end{array}$ & $\begin{array}{l}25 \text { Pediatric } \\
\text { patients } \\
5 \text { adult patients }\end{array}$ \\
\hline Lee et al. [46] & $\mathrm{NCI}$ & 21 & NA & $38 \%$ & $1 \times 10^{6}-3 \times 10^{6}$ & 67 & 57 & $\begin{array}{l}51.6 \% \text { at } \\
9.7 \text { months }\end{array}$ & $\begin{array}{l}\text { All pediatric or } \\
\text { young adults } \\
\text { (1-30 years) } \\
2 \text { Patients received } \\
\text { less than the } \\
\text { study doses }\end{array}$ \\
\hline
\end{tabular}

CAR chimeric antigen receptor, allo-SCT allogeneic stem cell transplant, $C R m$ molecular CR, EFS event free survival, $N A$ not available, $M S K C C$ Memorial Sloan Kettering Cancer Center, UPENN University of Pennsylvania, NCI National Cancer Institute

${ }^{a}$ One patient with CD19+ T-ALL

b Pediatric cohort \# adult cohort 
chemotherapies, the required $\mathrm{T}$ cell dose was achieved in all but 1 of the 16 unselected patients. In adults with chemorefractory disease, only a small minority $(5 \%)$ of patients receive a potentially curative allogeneic stem cell transplant (allo-SCT) because CR rates are $<30 \%$ and the few patients re-induced into a $\mathrm{CR}$ have many complications from aggressive salvage chemotherapy, precluding further treatment [47]. In contrast, the CR rate we obtained after CD19 CAR therapy was $88 \%$ [42]. Furthermore, these were high quality remissions as evidence by lack of detectable disease when assayed with high-sensitive molecular assays such as deep-sequencing or real-time PCR (molecular $\mathrm{CR}=75 \%$ ), raising the hope for durable remissions. In addition, while toxicities were noted they did not preclude patients from receiving an allo-SCT. The average time to CR was 24.5 days and $70 \%$ of the patients induced into a CR were later treated with an allo-SCT [42]. While the CAR T cells expanded rapidly, they also contracted rapidly and were detected at very low levels after 2-3 months posttransfer. Considering that molecular CRs were induced as early as 1 week post-CAR $\mathrm{T}$ transfer, longer persistence may not be required for optimal clinical outcomes, at least with CARs that contain a CD28 signaling domain.

Similar results were reported by the NCI [46] with their Phase I trial evaluating 19-28z CAR T cells for children and young adults (aged 1-30 years). This was a dose escalation trial $\left(1 \times 10^{6}, 3 \times 10^{6} \mathrm{CAR} \mathrm{T}\right.$ cells $/ \mathrm{kg}$, or entire product if it did not meet the previous two dose level requirements). 21 patients were enrolled, of which 2 were not treated at the required CAR T cell dose $(90 \%$ of target dose) and one had DLBCL. The CR rate for the 20 B-ALL patients was $70 \%(14 / 20)$ and molecular CR rate was $60 \%(12 / 20)$ [46]. In contrast to the NCI studies using CD19-targeted CAR T cells for NHL there was a correlation between CAR T cell expansion and response, however, persistence was still limited with no CAR T cells detected longer than 2 months after transfer. The limited persistence did not appear to affect long-term outcomes as all 12 patients with a molecular $\mathrm{CR}$ are still in remission and 10 were treated later with an allo-SCT [46]. As with our results for B-ALL it may be that rapid remissions, eight of the responding patients at the NCI had no circulating blasts by Day 7 of treatment, may offset the need for prolonged CAR T cell persistence.

The UPENN group published a case report of two pediatric B-ALL patients [45], which was later expanded to a cohort of 30 ( 25 pediatric and 5 adults patients); 1 of the subjects had CD19+ T-ALL [44]. The patients were most commonly conditioned with fludarabine and cyclophosphamide 1 week prior to adoptive transfer of $19 \mathrm{BBz}$ CAR $\mathrm{T}$ cells. The CAR T cell dose ranged from $0.8 \times 10^{6}$ to $17.4 \times 10^{6} \mathrm{CAR}$ T cells $/ \mathrm{kg}$. The CR rate was $90 \%(27 / 30)$ and molecular CR rate $73 \%$ (22/30, but 2 CR patients not assessed) [44]. As with the two other groups, clinical response overall correlated with CAR $\mathrm{T}$ expansion insofar that the three non-responders had the lowest level of circulating CAR T cells. Many of the pediatric patients had CAR T cell persistence with $68 \%$ showing continued T cell persistence at the 6 month time point and some showing detectable $\mathrm{T}$ cells for up to 2 years [44]. Thus, in the case of 4-1bb-based CARs, clinical outcomes appeared to correlate with long-term $\mathrm{T}$ cell persistence. The UPENN group also reported that six of the patients had loss of CAR $\mathrm{T}$ cells before relapse and three of these had recovery of normal B cells, an indirect marker for loss of CAR T function. The UPENN investigators also reported another form of relapse, CD19-negative clonal escape. In a follow-up study, [48] they suggested that these CD19-negative clonal escapes were due to pre-existing CD19-negative clones at the time of treatment, which suggests that future CAR therapy for B-ALL may benefit in some cases from the targeting of a second antigen, such as CD22, to prevent immune escape. Bi-specific CARs [49] that meet this combinatorial requirement, have been validated pre-clinically and are discussed in a later section.

\section{CAR T cell mediated toxicities}

\section{The cytokine release syndrome}

In the course of developing a new cancer therapeutic modality, CAR $\mathrm{T}$ cell investigators have encountered a unique set of $\mathrm{T}$ cell clinical toxicities that require careful diagnosis, monitoring, and management (Fig. 2). The large number of cases of CRS that has been documented in B-ALL, a more uniform disorder than NHL, allows a clearer examination of the relation of the CRS to $\mathrm{T}$ cell dose, conditioning and clinical response following CD19 CAR T cell infusion. Therefore, we will focus our discussion of toxicities on the five published reports of CD19targeted CAR T cells infused into patients with relapsed/ refractory B-ALL [42-46], noting that severe CRS also occurs in NHL and CLL subjects The CRS reported by different groups were remarkably similar and included a constellation of clinical signs reflecting intense inflammation that included fever, hypotension, tachycardia, and respiratory distress that initiated soon after CAR $\mathrm{T}$ cell infusion and progressed to a peak within days. The CRS was reported in 7 out of 16 patients by MSKCC, 22 out of 30 by the UPENN group, and 16 out of 21 of the patients treated by the NCI [42-46]. As the number of patients treated has increased there is a clear difference in the severities of CRS with some patients having mild to moderate CRS requiring only supportive management to others having a severe CRS requiring aggressive interventions. 


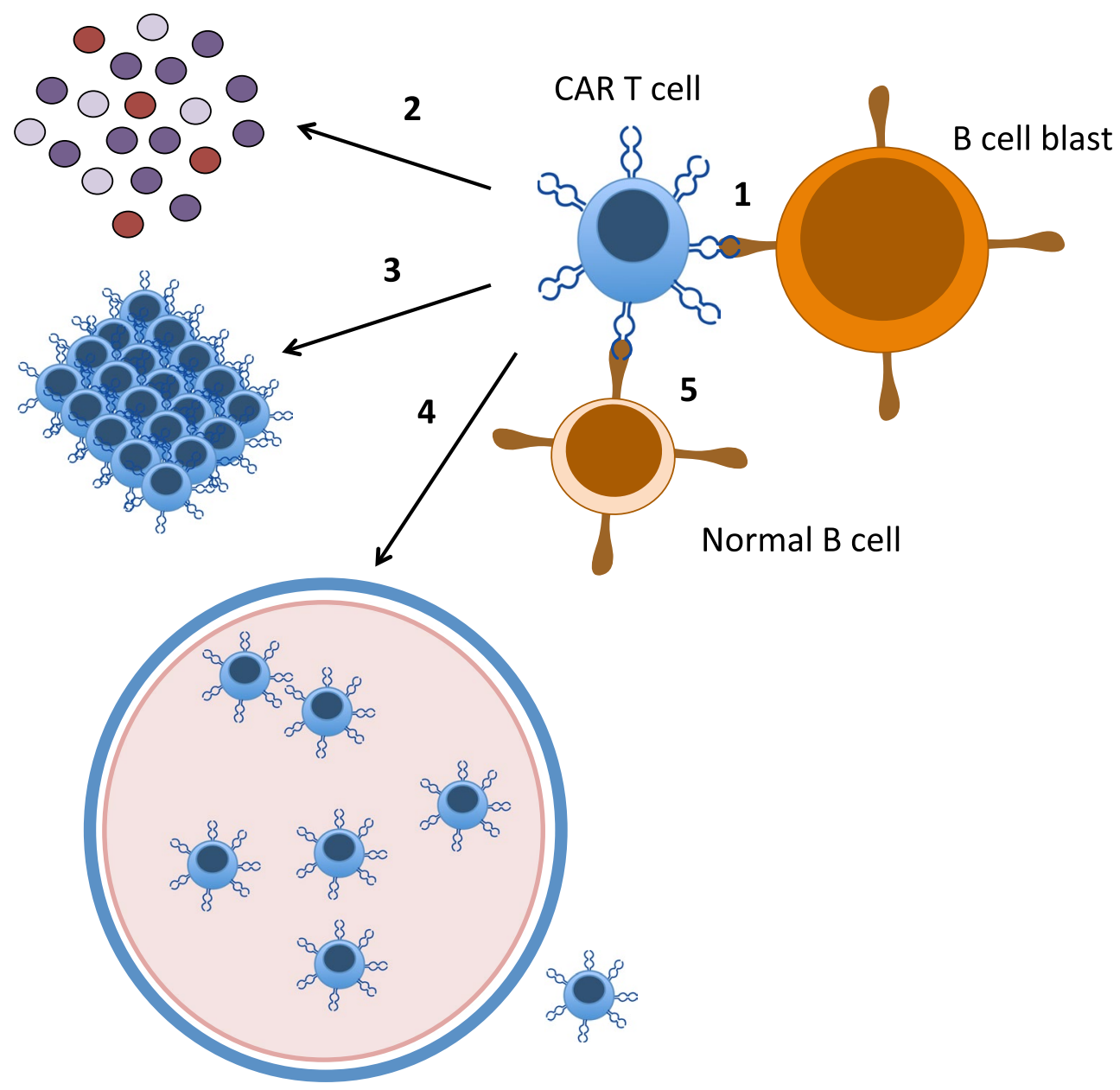

Fig. 2 Main CAR T cell functions. 1 A CAR T cell encounters the CD19 antigen on B cell blasts and initiates tumor killing. Engagement of CD19 by CAR T cells also leads to 2 massive cytokine production and 3 cell proliferation, which results in cytokine release syndrome toxicities and leukemia eradication. Some CAR T cells are able to access the CNS by 4 potentially crossing the blood brain bar- rier (BBB) from capillaries and presumably mediate neurotoxicities, directly or indirectly. In addition to killing malignant B cells, CD19targeted CAR T cells will 5 engage and kill normal B cells resulting in $\mathrm{B}$ cell aplasia that lasts for as long as the CAR T cells persist and remain functional
The MSKCC group provided important insight when they demonstrated that severe CRS is associated with tumor burden, which has been confirmed by the groups at the NCI and UPENN [42-46]. This suggests that a large tumor burden results in massive activation of infused CAR $\mathrm{T}$ cells and robust expansion of CD19-targeted CAR T cells, especially CD8 and effector memory cells. Presumably, the activated CAR $\mathrm{T}$ cells secrete cytokines that activate other immune cells, which secrete their own cytokines creating a whirlwind of inflammation. All groups have used steroids and/or the anti-IL6 receptor antibody, tocilizumab, to treat the CRS. These agents have both worked well at ameliorating the toxicities, however, we demonstrated that steroids could impact CAR T cell expansion, which was associated with early relapses [42]. Therefore, tocilizumab, which does not appear to inhibit CAR T cell expansion but elevates serum IL-6, is considered the first line agent for managing CRS.

As CAR T cell trials are exported to other academic medical centers there has been a concentrated effort to diagnose, classify, and manage the CRS. The MSKCC group has developed diagnostic criteria [42] consisting of clinical and laboratory results, while others have developed a grading scheme for CRS [50]. On June 10, 2015, the Recombination DNA Advisory Committee (RAC) of the Office of Biotechnology Activities and National Institutes of Health held a public meeting with investigators to discuss the clinical elements and management of the CRS (http://osp. od.nih.gov/office-biotechnology-activities/event/2015-0609-160000-2015-06-10-210000/rac-meeting). One of the follow-up items developed by this committee is the need for the various investigators to develop a unified definition 
of CRS and grading. All the groups have developed clinical management algorithms that reserve treatment with CRS attenuating agents for those with severe CRS [42-46, 50]. Importantly, despite the lymphotoxic nature of steroids they remain a viable treatment option if the patient is not responding to cytokine blocking agents. These patients may be offered an allo-SCT if there is a concern for an increased chance for relapse [42]. An important part of this management scheme is the use of a biomarker to monitor for patients at risk of severe CRS requiring intensive monitoring and potential interventions. The MSKCC group validated the CRP and determined patients with levels $>20 \mathrm{mg} /$ $\mathrm{dL}$ are at great risk for developing complications related to severe CRS requiring aggressive clinical interventions [42]. The UPENN and MSKCC groups have confirmed that CRP levels correlate with severity of CRS further highlighting the utility of this rapid, reliable laboratory test that can be followed daily $[44,46]$.

\section{Neurotoxicity}

Patients with CRS may also display a constellation of neurologic toxicities, which are wide-ranging in severity and sometimes progressive $[42,44,46]$. These neurotoxicities may be a generalized complication of widespread T-mediated inflammation or follow a different mechanism. It is noteworthy that similar neurotoxicity has been described in patients treated with bi-specific $\mathrm{T}$ cell engagers or antiCD28 antibodies [51, 52]. Patients can display word-finding difficulties or become aphasic, while others can be confused or obtunded to the point they require intubation for airway protection. While the CRS and neurotoxicity commonly occur in the same patients, it is increasingly believed they are distinct entities. There is some indirect evidence for a role of CAR T cells and neurotoxicity. Multiple groups have identified CAR $\mathrm{T}$ cells in the cerebrospinal fluid (CSF) of patients [42, 44, 46], although these findings do not clearly correlate with clinical neurotoxicity In some cases, $\mathrm{T}$ cells in the CSF may relate to leukemia in the central nervous system (CNS) of patients. However, patients with CD19-targeted CAR T cells in the CSF have also been detected in patients without detectable B-ALL in their CNS [42, 44, 46]. Another concerning possibility would be direct activation by CNS tissue.

Most centers have reported the neurotoxicities appear to be self-limited and patients recover without long-term neurologic deficits $[42,44,46]$. At this time there is no clear clinical standard for managing neurotoxicities and interventions can include prophylaxis, supportive care alone, or medications. There have been no reports of the efficacy of prophylaxis at either preventing or reducing the severity of neurotoxicity. In our experience, neurologic toxicities have not responded to or been prevented in patients treated with tocilizumab for CRS even if the CRS has completely abated. This may be due to the inability of the anti-IL6 receptor antibody to pass the blood brain barrier. We have had some success with dexamethasone but have also shown that it can inhibit CAR T cell expansion [42].

\section{On-target off-tumor toxicities}

Another toxicity, described as "on-target off-tumor", is due to CAR target antigen expression in normal cells. In the worst case this could result in death if there is surreptitious expression on vital tissues. This may have been observed in a case report with the respiratory arrest of a patient with metastatic colorectal cancer after treatment with ERBB2specific CAR T cells [53], although the cause of death was not fully elucidated. It has been assumed that low-level ERBB2 expression on respiratory epithelium was targeted by the CAR T cells resulting in fatal toxicities shortly after $\mathrm{T}$ cell infusion. This highlights the importance of target discovery and validation when developing CARs against other cancers. Fortunately, this extreme case has not been re-capitulated elsewhere with other CAR targets.

The best described form of on-target off tumor toxicity is B cell aplasia. CD19 is expressed on malignant B cells but also turned on in early B cell development and not extinguished until plasma cell differentiation [54]. Therefore, it was suspected that normal B cells would be eradicated along with malignant B cells. Indeed, all groups have reported evidence of B cell aplasia with few to no B cells in the blood and BM of selected patients [20, 27, 29, 42-46]. Furthermore, the persistence of B cell aplasia appears to be dependent on CAR T cell persistence. Therefore, B cell aplasia in patients treated by the NCI and MSKCC groups was limited to a few months, but in some UPENN patients it can last over a year [20, 27, 29, 42-46]. While the B cell aplasia in these patients can be managed with antibiotics and/or infusional gamma globulin, it is a concern that longer periods of B cell aplasia may severely impact morbidity and/or mortality.

\section{Future directions}

The next decade will determine if CAR T cells are not only effective against B cell malignancies but can be adapted as a general cancer therapy. The disparate efficacies of CD19 CAR T cells against B-ALL vs. NHL demonstrate that the underlying disease may influence the response to CAR therapy targeting the same antigen. The biology of different cancers will thus have to be taken in account in the development of CAR therapy for solid tumors. Adapting CAR therapy to solid malignancies will also require the identification of suitable tumor antigen targets. CD19 and its B 
lineage-restricted expression limited the potential for ontarget off-tumor toxicities, but a poor target choice could result in significant toxicity.

Recent pre-clinical advances in CAR design offer potential solutions for these challenges. Thus, "armored" CAR T cells represent an exciting potential innovation in CAR design that aims to alter the tumor microenvironment (TME) to promote immune function. In contrast to solely enhancing intrinsic $\mathrm{T}$ cell potency through the CAR, armored CARs are engineered to affect the TME. For example, a pro-tumor cytokine milieu in the TME can attenuate cytotoxicity and skew towards ineffective Th2-based $\mathrm{T}$ cell responses. However, T cells engineered to express a secondgeneration CAR and also secrete IL-12 can potentiate T cell cytotoxicity of tumor cells due to pro-tumoricidal effects of IL-12 in the TME [55, 56]. Another novel CAR design in the armored CAR category includes combining secondgeneration CARs with an autonomous co-stimulatory ligand $[41,57]$. This advance allows CAR T cells to supporting auto-co-stimulation even if the TME lacks such ligands. The co-stimulatory ligands can also activate other nonCAR transduced tumor-reactive $\mathrm{T}$ cells infiltrating into the TME, known as trans-costimulation. Another CAR design that addresses the immune suppressive TME isPD1/CD28 chimeric receptor that when paired with a CAR allows conversion of a negative stimulus to a positive stimulus for the infiltrating tumor-reactive T cell [58-61].

Another interesting advance to enhance safety and/or efficacy is the creation of bi-specific CARs. T cells genetically modified to express two fully autonomous CARs (CAR1 and CAR2) specific for two distinct tumor antigens may reduce the risk of immune escape by tumor antigen down-regulation [49, 62]. A different combinatorial targeting principle was used to limit off-tumor activity, by coexpressing a CAR and a CCR $[49,62]$. In this case, ligation of the CAR or CCR by its respective antigen alone is insufficient to induce full $\mathrm{T}$ cell activation. However, when both are ligated their activation and co-stimulatory domains combine to support full activation. This concept was further modified with the use of a synthetic Notch receptor (synNotch) modified to bind a cell surface antigen, upon which Notch signaling induces expression of a CAR that is specific for a second antigen [63].

Another iteration of combinatorial targeting makes use of the iCAR (inhibitory CAR), which can also be used to enhance safety when concerned about off-target expression of tumor antigens. In this case, the iCAR is coexpressed with a CAR endowed with a full complement of activation and co-stimulatory domains, which can be regulated by engagement of an iCAR with PD-1 activity [64]. Therefore, ligation of CAR activates the $\mathrm{T}$ cell against the tumor cell expressing the target antigen, but the iCAR curbs this activity against normal cells that express both antigens, directing reversible inhibition of the T cell [64].

Impressive clinical successes in treating patients with chemotherapy-refractory, relapsed and predictably fatal B cell malignancies, have been obtained with autologous CD19 CAR T cells, particularly in B-ALL. CD19 CAR $\mathrm{T}$ cells for B-ALL is likely to be the first adoptive $\mathrm{T}$ cell therapy to gain regulatory approval. However, CAR T cells will only become a general form of cancer therapy if it can be adapted to other cancers. While these other cancers will likely present additional challenges to overcome, novel CAR designs are poised to increase the safety and efficacy of this powerful cancer immunotherapy.

\section{Compliance with ethical standards}

Conflict of interest MLD has no relevant conflict of interests to disclose. MS is a consultant for Juno Therapeutics.

\section{References}

1. Williams MA, Bevan MJ. Effector and memory CTL differentiation. Annu Rev Immunol. 2007;25:171-92.

2. Abraham RT, Weiss A. Jurkat T cells and development of the T-cell receptor signalling paradigm. Nat Rev Immunol. 2004;4(4):301-8.

3. Irving BA, Weiss A. The cytoplasmic domain of the T cell receptor zeta chain is sufficient to couple to receptor-associated signal transduction pathways. Cell. 1991;64(5):891-901.

4. Coulie PG, Uyttenhove C, Wauters P, Manolios N, Klausner RD, Samelson LE, et al. Identification of a murine monoclonal antibody specific for an allotypic determinant on mouse CD3. Eur J Immunol. 1991;21(7):1703-9.

5. Letourneur F, Klausner RD. Activation of $\mathrm{T}$ cells by a tyrosine kinase activation domain in the cytoplasmic tail of CD3 epsilon. Science. 1992;255(5040):79-82.

6. Eshhar Z, Waks T, Gross G, Schindler DG. Specific activation and targeting of cytotoxic lymphocytes through chimeric single chains consisting of antibody-binding domains and the gamma or zeta subunits of the immunoglobulin and T-cell receptors. Proc Natl Acad Sci USA. 1993;90(2):720-4.

7. Brocker T, Peter A, Traunecker A, Karjalainen K. New simplified molecular design for functional T cell receptor. Eur J Immunol. 1993;23(7):1435-9.

8. Sadelain M, Brentjens R, Riviere I. The promise and potential pitfalls of chimeric antigen receptors. Curr Opin Immunol. 2009;21(2):215-23.

9. Gong MC, Latouche JB, Krause A, Heston WD, Bander NH, Sadelain M. Cancer patient $\mathrm{T}$ cells genetically targeted to prostate-specific membrane antigen specifically lyse prostate cancer cells and release cytokines in response to prostate-specific membrane antigen. Neoplasia. 1999;1(2):123-7.

10. Brocker T, Karjalainen K. Signals through T cell receptor-zeta chain alone are insufficient to prime resting $\mathrm{T}$ lymphocytes. J Exp Med. 1995;181(5):1653-9.

11. Krause A, Guo HF, Latouche JB, Tan C, Cheung NK, Sadelain M. Antigen-dependent CD28 signaling selectively enhances survival and proliferation in genetically modified activated human primary T lymphocytes. J Exp Med. 1998;188(4):619-26. 
12. Maher J, Brentjens RJ, Gunset G, Riviere I, Sadelain M. Human T-lymphocyte cytotoxicity and proliferation directed by a single chimeric TCRzeta/CD28 receptor. Nat Biotechnol. 2002;20(1):70-5.

13. Rosenberg SA, Packard BS, Aebersold PM, Solomon D, Topalian SL, Toy ST, et al. Use of tumor-infiltrating lymphocytes and interleukin-2 in the immunotherapy of patients with metastatic melanoma. A preliminary report. $\mathrm{N}$ Engl $\mathrm{J}$ Med. 1988;319(25):1676-80.

14. Hollyman D, Stefanski J, Przybylowski M, Bartido S, BorquezOjeda O, Taylor C, et al. Manufacturing validation of biologically functional $\mathrm{T}$ cells targeted to CD19 antigen for autologous adoptive cell therapy. J Immunother. 2009;32(2):169-80.

15. Imai C, Mihara K, Andreansky M, Nicholson IC, Pui CH, Geiger TL, et al. Chimeric receptors with 4-1BB signaling capacity provoke potent cytotoxicity against acute lymphoblastic leukemia. Leukemia. 2004;18(4):676-84.

16. van der Stegen SJ, Hamieh M, Sadelain M. The pharmacology of second-generation chimeric antigen receptors. Nat Rev Drug Discov. 2015;14(7):499-509.

17. Wang X, Riviere I. Manufacture of tumor- and virus-specific $\mathrm{T}$ lymphocytes for adoptive cell therapies. Cancer Gene Ther. 2015;22(2):85-94.

18. Jensen MC, Popplewell L, Cooper LJ, DiGiusto D, Kalos M, Ostberg JR, et al. Antitransgene rejection responses contribute to attenuated persistence of adoptively transferred CD20/CD19specific chimeric antigen receptor redirected $\mathrm{T}$ cells in humans. Biol Blood Marrow Transplant. 2010;16(9):1245-56.

19. Beatty GL, Haas AR, Maus MV, Torigian DA, Soulen MC, Plesa $\mathrm{G}$, et al. Mesothelin-specific chimeric antigen receptor mRNAengineered $\mathrm{T}$ cells induce anti-tumor activity in solid malignancies. Cancer Immunol Res. 2014;2(2):112-20.

20. Kalos M, Levine BL, Porter DL, Katz S, Grupp SA, Bagg A, et al. $\mathrm{T}$ cells with chimeric antigen receptors have potent antitumor effects and can establish memory in patients with advanced leukemia. Sci Transl Med. 2011;3(95):95ra73.

21. Wang $\mathrm{X}$, Olszewska $\mathrm{M}, \mathrm{Qu} \mathrm{J}$, Wasielewska T, Bartido $\mathrm{S}$, Hermetet $G$, et al. Large-scale clinical-grade retroviral vector production in a fixed-bed bioreactor. $\mathrm{J}$ Immunother. 2015;38(3):127-35.

22. Fischer A, Abina SH, Thrasher A, von Kalle C, Cavazzana-Calvo $\mathrm{M}$. LMO2 and gene therapy for severe combined immunodeficiency. N Engl J Med. 2004;350(24):2526-7 (author reply 26-7).

23. Hacein-Bey-Abina S, Von Kalle C, Schmidt M, McCormack MP, Wulffraat N, Leboulch P, et al. LMO2-associated clonal T cell proliferation in two patients after gene therapy for SCID-X1. Science. 2003;302(5644):415-9.

24. Eyquem J, Mansilla-Soto J, Odak A, Sadelain M. ASGCT 2016 Meeting. Mol Ther. 2016;24(Supplement):S109.

25. Savoldo B, Ramos CA, Liu E, Mims MP, Keating MJ, Carrum $\mathrm{G}$, et al. CD28 costimulation improves expansion and persistence of chimeric antigen receptor-modified T cells in lymphoma patients. J Clin Invest. 2011;121(5):1822-6.

26. Till BG, Jensen MC, Wang J, Chen EY, Wood BL, Greisman HA, et al. Adoptive immunotherapy for indolent non-Hodgkin lymphoma and mantle cell lymphoma using genetically modified autologous CD20-specific T cells. Blood. 2008;112(6):2261-71.

27. Brentjens RJ, Riviere I, Park JH, Davila ML, Wang X, Stefanski J, et al. Safety and persistence of adoptively transferred autologous CD19-targeted $\mathrm{T}$ cells in patients with relapsed or chemotherapy refractory B-cell leukemias. Blood. 2011;118(18):4817-28.

28. Porter DL, Levine BL, Kalos M, Bagg A, June CH. Chimeric antigen receptor-modified $\mathrm{T}$ cells in chronic lymphoid leukemia. N Engl J Med. 2011;365(8):725-33.
29. Kochenderfer JN, Dudley ME, Feldman SA, Wilson WH, Spaner DE, Maric I, et al. B-cell depletion and remissions of malignancy along with cytokine-associated toxicity in a clinical trial of antiCD19 chimeric-antigen-receptor-transduced $\mathrm{T}$ cells. Blood. 2012;119(12):2709-20.

30. Kochenderfer JN, Wilson WH, Janik JE, Dudley ME, StetlerStevenson M, Feldman SA, et al. Eradication of B-lineage cells and regression of lymphoma in a patient treated with autologous $\mathrm{T}$ cells genetically engineered to recognize CD19. Blood. 2010;116(20):4099-102.

31. Brentjens RJ, Latouche JB, Santos E, Marti F, Gong MC, Lyddane $\mathrm{C}$, et al. Eradication of systemic B-cell tumors by genetically targeted human T lymphocytes co-stimulated by CD80 and interleukin-15. Nat Med. 2003;9(3):279-86.

32. Sadelain M. CAR therapy: the CD19 paradigm. J Clin Invest. 2015;125(9):3392-400.

33. Davila ML, Brentjens R, Wang X, Riviere I, Sadelain M. How do CARs work?: early insights from recent clinical studies targeting CD19. Oncoimmunology. 2012;1(9):1577-83.

34. Porter DL, Hwang WT, Frey NV, Lacey SF, Shaw PA, Loren $\mathrm{AW}$, et al. Chimeric antigen receptor $\mathrm{T}$ cells persist and induce sustained remissions in relapsed refractory chronic lymphocytic leukemia. Sci Transl Med. 2015;7(303):303ra139.

35. Kochenderfer JN, Dudley ME, Kassim SH, Somerville RP, Carpenter RO, Stetler-Stevenson M, et al. Chemotherapy-refractory diffuse large B-cell lymphoma and indolent B-cell malignancies can be effectively treated with autologous $\mathrm{T}$ cells expressing an anti-CD19 chimeric antigen receptor. J Clin Oncol. 2015;33(6):540-9.

36. Kochenderfer JN, Somerville R, Lu L, Iwamoto A, Yang JC, Klebanoff C, et al. Anti-CD19 CAR T cells administered after low-dose chemotherapy can induce remissions of chemotherapy-refractory diffuse large B-cell lymphoma. Blood. 2014;124(21):550.

37. Turtle CJ, Berger C, Sommermeyer D, Hanafi L-A, Pender B, Robinson EM, et al. Anti-CD19 chimeric antigen receptormodified $\mathrm{T}$ cell therapy for $\mathrm{B}$ cell non-Hodgkin lymphoma and chronic lymphocytic leukemia: fludarabine and cyclophosphamide lymphodepletion improves in vivo expansion and persistence of CAR-T cells and clinical outcomes. Blood. 2015;126(23):184.

38. Schuster SJ, Svoboda J, Dwivedy Nasta S, Porter DL, Chong EA, Landsburg DJ, et al. Sustained remissions following chimeric antigen receptor modified $\mathrm{T}$ cells directed against CD19 (CTL019) in patients with relapsed or refractory CD19+ lymphomas. Blood. 2015;126(23):183.

39. Locke FL, Neelapu SS, Bartlett NL, Siddiqi T, Chavez JC, Hosing CM, et al. Phase 1 clinical results of the ZUMA-1 (KTEC19-101) study: a phase 1-2 multi-center study evaluating the safety and efficacy of anti-CD19 CAR T cells (KTE-C19) in subjects with refractory aggressive non-Hodgkin lymphoma (NHL). Blood. 2015;126(23):3991.

40. Fraietta JA, Beckwith KA, Patel PR, Ruella M, Zheng Z, Barrett $\mathrm{DM}$, et al. Ibrutinib enhances chimeric antigen receptor T-cell engraftment and efficacy in leukemia. Blood. 2016;127(9):1117-27.

41. Zhao Z, Condomines M, van der Stegen SJ, Perna F, Kloss CC, Gunset G, et al. Structural design of engineered costimulation determines tumor rejection kinetics and persistence of CAR T cells. Cancer Cell. 2015;28(4):415-28.

42. Davila ML, Riviere I, Wang X, Bartido S, Park J, Curran K, et al. Efficacy and toxicity management of $19-28 \mathrm{z}$ CAR $\mathrm{T}$ cell therapy in B cell acute lymphoblastic leukemia. Sci Transl Med. 2014;6(224):224ra25.

43. Brentjens RJ, Davila ML, Riviere I, Park J, Wang X, Cowell LG, et al. CD19-targeted $\mathrm{T}$ cells rapidly induce molecular remissions 
in adults with chemotherapy-refractory acute lymphoblastic leukemia. Sci Transl Med. 2013;5(177):177ra38.

44. Maude SL, Frey N, Shaw PA, Aplenc R, Barrett DM, Bunin NJ, et al. Chimeric antigen receptor $\mathrm{T}$ cells for sustained remissions in leukemia. N Engl J Med. 2014;371(16):1507-17.

45. Grupp SA, Kalos M, Barrett D, Aplenc R, Porter DL, Rheingold $\mathrm{SR}$, et al. Chimeric antigen receptor-modified $\mathrm{T}$ cells for acute lymphoid leukemia. N Engl J Med. 2013;368(16):1509-18.

46. Lee DW, Kochenderfer JN, Stetler-Stevenson M, Cui YK, Delbrook C, Feldman SA, et al. T cells expressing CD19 chimeric antigen receptors for acute lymphoblastic leukaemia in children and young adults: a phase 1 dose-escalation trial. Lancet. 2015;385(9967):517-28.

47. Thomas DA, Kantarjian H, Smith TL, Koller C, Cortes J, O'Brien S, et al. Primary refractory and relapsed adult acute lymphoblastic leukemia: characteristics, treatment results, and prognosis with salvage therapy. Cancer. 1999;86(7):1216-30.

48. Sotillo E, Barrett DM, Black KL, Bagashev A, Oldridge D, Wu $\mathrm{G}$, et al. Convergence of acquired mutations and alternative splicing of CD19 enables resistance to CART-19 immunotherapy. Cancer Discov. 2015;5(12):1282-95.

49. Kloss CC, Condomines M, Cartellieri M, Bachmann M, Sadelain M. Combinatorial antigen recognition with balanced signaling promotes selective tumor eradication by engineered T cells. Nat Biotechnol. 2013;31(1):71-5.

50. Lee DW, Gardner R, Porter DL, Louis CU, Ahmed N, Jensen $\mathrm{M}$, et al. Current concepts in the diagnosis and management of cytokine release syndrome. Blood. 2014;124(2):188-95.

51. Teachey DT, Rheingold SR, Maude SL, Zugmaier G, Barrett $\mathrm{DM}$, Seif $\mathrm{AE}$, et al. Cytokine release syndrome after blinatumomab treatment related to abnormal macrophage activation and ameliorated with cytokine-directed therapy. Blood. 2013;121(26):5154-7.

52. Suntharalingam G, Perry MR, Ward S, Brett SJ, Castello-Cortes $\mathrm{A}$, Brunner MD, et al. Cytokine storm in a phase 1 trial of the anti-CD28 monoclonal antibody TGN1412. N Engl J Med. 2006;355(10):1018-28.

53. Morgan RA, Yang JC, Kitano M, Dudley ME, Laurencot CM, Rosenberg SA. Case report of a serious adverse event following the administration of $\mathrm{T}$ cells transduced with a chimeric antigen receptor recognizing ERBB2. Mol Ther. 2010;18(4):843-51.

54. Yazawa N, Hamaguchi Y, Poe JC, Tedder TF. Immunotherapy using unconjugated CD19 monoclonal antibodies in animal models for B lymphocyte malignancies and autoimmune disease. Proc Natl Acad Sci USA. 2005;102(42):15178-83.

55. Pegram HJ, Lee JC, Hayman EG, Imperato GH, Tedder TF, Sadelain M, et al. Tumor-targeted T cells modified to secrete IL-12 eradicate systemic tumors without need for prior conditioning. Blood. 2012;119(18):4133-41.

56. Chmielewski M, Abken H. CAR T cells transform to trucks: chimeric antigen receptor-redirected $\mathrm{T}$ cells engineered to deliver inducible IL-12 modulate the tumour stroma to combat cancer. Cancer Immunol Immunother. 2012;61(8):1269-77.

57. Stephan MT, Ponomarev V, Brentjens RJ, Chang AH, Dobrenkov $\mathrm{KV}$, Heller G, et al. T cell-encoded CD80 and 4-1BBL induce auto- and transcostimulation, resulting in potent tumor rejection. Nat Med. 2007;13(12):1440-9.

58. Prosser ME, Brown CE, Shami AF, Forman SJ, Jensen MC. Tumor PD-L1 co-stimulates primary human CD8(+) cytotoxic $\mathrm{T}$ cells modified to express a PD1:CD28 chimeric receptor. Mol Immunol. 2012;51(3-4):263-72.

59. Liu X, Ranganathan R, Jiang S, Fang C, Sun J, Kim S, et al. A chimeric switch-receptor targeting PD1 augments the efficacy of second-generation CAR T cells in advanced solid tumors. Cancer Res. 2016;76(6):1578-90.

60. Ankri C, Shamalov K, Horovitz-Fried M, Mauer S, Cohen CJ Human $\mathrm{T}$ cells engineered to express a programmed death $1 / 28$ costimulatory retargeting molecule display enhanced antitumor activity. J Immunol. 2013;191(8):4121-9.

61. Kobold S, Grassmann S, Chaloupka M, Lampert C, Wenk S, Kraus F, et al. Impact of a new fusion receptor on PD-1-mediated immunosuppression in adoptive $\mathrm{T}$ cell therapy. $\mathrm{J}$ Natl Cancer Inst. 2015;107(8):1-10.

62. Lanitis E, Poussin M, Klattenhoff AW, Song D, Sandaltzopoulos $\mathrm{R}$, June $\mathrm{CH}$, et al. Chimeric antigen receptor T Cells with dissociated signaling domains exhibit focused antitumor activity with reduced potential for toxicity in vivo. Cancer Immunol Res. 2013;1(1):43-53.

63. Roybal KT, Rupp LJ, Morsut L, Walker WJ, McNally KA, Park JS, et al. Precision tumor recognition by T cells with combinatorial antigen-sensing circuits. Cell. 2016;164(4):770-9.

64. Fedorov VD, Themeli M, Sadelain M. PD-1- and CTLA4-based inhibitory chimeric antigen receptors (iCARs) divert off-target immunotherapy responses. Sci Transl Med. 2013;5(215):215ra172. 